\title{
PRINCIPIO DE COMPLETITUD DE LA LEY ESCRITA Y CREACIÓN JUDICIAL DEL DERECHO EN CONFLICTOS CONTRACTUALES CIVILES
}

\author{
Antonio Bohórquez Orduz* \\ Recibido: Abril 30 de 2016 \\ Aprobado: Mayo 30 de 2016
}

\begin{abstract}
RESUMEN
Según el sistema político jurídico, la Sala Civil de la Corte Suprema de Justicia no está legitimada para crear normas. Esto deja entrever una visión distinta desde la práctica. En este texto se evidencia a partir de análisis líneas jurisprudenciales en conflictos contractuales de derecho privado, la respuesta afirmativa a la hipótesis de la existencia de una creación Judicial del Derecho donde los jueces sí crean derecho y terminan por superar los vacíos que la ley ofrece. No obstante, han de soportarse en razones suficientes de su proceder y a su vez, armonizar con el sistema.
\end{abstract}

Palabras clave: Creación judicial, completitud, legitimidad, conflictos contractuales

\section{PRINCIPLE OF COMPLETENESS OF THE WRITTEN LAW AND JUDICIAL CREATION OF RIGHTS IN CONTRACTUAL CIVIL CONFLICTS}

\begin{abstract}
According to the legal-political system, the Civil Chamber of the Supreme Court is not legitimized to create legal norms. This suggests a different view from practice. This article focuses on the affirmative response to the hypothesis of the existence of a judicial creation of law.

* Abogado egresado de la Universidad Autónoma de Bucaramanga. Doctor en Derecho Cum Lauden de la Universidad Externado de Colombia. Especialista en Derecho Comercial de la Universidad Autónoma de Bucaramanga. Docente de Pregrado y Posgrado. Doctrinante. Magistrado de la Sala Civil del Tribunal

Superior de Bucaramanga.
\end{abstract}


Judges do create law and eventually fill gaps. However, they have to justify their proceedings and harmonize them with the legal system.

Keywords: judicial creation of law, completeness, legitimacy, contractual civil conflicts.

\section{PRINCÍPIO DE COMPLETITUDE DA LEI ESCRETA E CRIAÇÃO JUDICIAL DO DIREITO EM CONFLITOS CONTRATUAIS CIVIES}

\section{RESUMO}

De acordo com o sistema político jurídico, a Câmara do Supremo Tribunal Civil não tem o direito de criar normas. Isto sugere uma visão diferente da prática. Neste texto é evidente a partir de análise de linhas jurisprudenciais em conflitos contratuais de direito privado, a resposta afirmativa à hipótese da existência de uma criação judicial do direito onde os juízes criam lei e eventualmente enchem os vazíos que a lei oferece. No entanto, eles devem se apoiar em razões suficientes do seu proceder, e assim harmonizar com o sistema.

Palavras-chave: Criação Judicial, completitude , legitimidade , conflitos contratuais

\section{INTRODUCCIÓN}

La decisión judicial, tema nodal de esta investigación, a veces es entendida como un ejercicio de subsunción y, otras, como una labor de creación del derecho; y entre los dos extremos, un sinnúmero de matices y posibilidades. En esa reflexión se inserta el problema de investigación de del trabajo que se presenta:

¿El juez (la Sala civil de la Corte Suprema de Justicia) ante la falta de completitud o la insuficiencia de la codificación, está legitimado para construir normas generales que le permitan resolver el caso particular o sólo lo está para aplicar las preexistentes?

El trabajo pretende demostrar la hipótesis según la cual, la Sala Civil de la Corte Suprema de Justicia tiene legitimidad para crear normas, aun cuando el sistema político jurídico aparentemente no se la reconozca; y la Corte lo ha venido haciendo aunque no lo admita, desde el siglo XIX. 
El medio elegido para escudriñar el punto fue el de observar las sentencias y cotejarlas con el sistema jurídico. Como no era posible limitar el estudio a un tema, o a una época, pues ello ofrecería una falsa impresión del trabajo de la Corte y habría amenazado la validez de los resultados de la investigación, la demarcación del objeto material de investigación se hizo por líneas jurisprudenciales relativas a conflictos contractuales de derecho privado; $y$, entre estas, como el número resultaba aún muy alto, hubo de tomarse unas, a manera de muestreo.

Primero se hablará del principio de la completitud de la ley escrita; luego se mostrará cómo ese principio se aplica en la jurisprudencia colombiana. En tercer lugar se analizará cuál es la tesis del derecho de la posmodernidad y su aplicación en la definición de conflictos contractuales de derecho privado de nuestra era, para pasar a mirar cómo fue trasplantado ese principio a nuestro derecho. Para culminar, se hará alusión a la legitimidad de la función creativa de la Corte y a las más importantes conclusiones de la investigación.

\section{LA TESIS CLÁSICA DE NUESTRA CULTURA JURÍDICA: LA COMPLETITUD DE LA LEY ESCRITA}

Suele afirmarse que el juez identifica los hechos relevantes, determina la norma en la cual caben tales hechos y encuentra en ella la consecuencia que es el decisum de la sentencia. El proceder, llamado subsunción, se sostiene sobre un presupuesto de carácter político jurídico, heredado de la cultura francesa del siglo XIX, el principio de completitud de la norma escrita: el Derecho era el Code y nada más que el Code. De allí las normas que obligan al juez a fallar siempre, que le prohíben crear reglas, pero que también le prohíben esgrimir como pretexto la insuficiencia de la ley para abstenerse de decidir. Y la abundancia de disposiciones era señal de plenitud; en contratos, por ejemplo, trece títulos de la obra los regulaban.

Se entiende así que haya tomado fuerza el método exegético de interpretación de la ley, a pesar de que hunde sus raíces en el absolutismo: el monarca se presumía sabio porque la autoridad le venía de Dios. Los revolucionarios liberales no abolieron ese criterio; más bien lo adaptaron y lo llevaron a su apogeo: el legislador se presume sabio

1 Code Civil des Français fue el título original del código. En 1807 se le otorgó, oficialmente el título de Code Napoleón. En 1870 se le dio la denominación oficial de Code Civil, pero por razones históricas se le sigue llamando por la doctrina Código Napoleónico. 
porque la autoridad le viene del pueblo. El caos de la administración de justicia de la larga Edad Media y el uso político que le daban los gobernantes, era parte del ancien régime por erradicar. Robespierre propuso incluso borrar del idioma la expresión jurisprudencia (citado por Geny, 1925). Así surgió una de las grandes conquistas de la humanidad: la separación de poderes (Simon, 1985).

Según Laporta (2007), solo si los jueces están sometidos a la ley se logra seguridad jurídica, se garantiza la autonomía de las personas y se cumple el sueño liberal de que las leyes constituyan la mayor garantía de las libertades individuales. Napoleón creía que su Código tenía esa virtud. Diría el emperador ya en el exilio: "Allí donde planté el Código Civil, yo sembré la libertad" (citado por Bredín, 2004). Era tal el culto por la obra legislativa que nuestro Hombre de las Leyes llegó a decir, "la Constitución y las leyes se cumplirán; si estas mandan hacer el bien, el bien se hará, si el mal, el mal se hará" ${ }^{2}$. Así, la labor del intérprete de la ley era solo la de averiguar la voluntad del legislador, cualquiera que ella fuese.

Pero en el mismo siglo XIX, muchos jueces franceses concretaban el derecho de manera diferente a la de aquella labor mecánica supuesta por el famoso texto montesquiano, con la ayuda de las obras de los insignes romanistas conocidos como los padres del Código Napoleónico (Recaséns, 1980). Incluso se habló de una "tercera vida" del derecho romano(Zimmermann, 2010). Como cita Geny (1925), numerosas decisiones del Tribunal de Casación Francés de ese siglo, fueron dadas como "puras interpretaciones de la ley" (p.235). Eran más bien muestra de insuficiencia de la ley.

\subsection{La aplicación actual de la tesis clásica en la jurisprudencia colombiana}

Esa tesis clásica pasó a ser la postura más usual en los administradores de justicia nuestros, como resultado de un proceso cultural venido de Francia, que no es reprochable per se, pues cuando la Corte Suprema de Justicia asume una postura que se acostumbra tildar de legalista, sin descartar eventuales errores, en realidad responde a su vocación democrática y amante de las libertades de los asociados.

2 Palabras del General Francisco de Paula Santander, al tomar posesión del cargo de vicepresidente de la República el 7 de septiembre de 1821. 
Por este flanco, el trabajo analiza cuatro líneas jurisprudenciales. La primera, es la relativa a las normas que establecen formalidades para las compraventas de inmuebles, nada censurable, en aras de principios como la seguridad, la certeza y el interés público. La segunda se refiere a la posición de la Corte, casi constante, de dar aplicación estricta al artículo 1546 del Código Civil, atinente a los presupuestos de la resolución de los contratos, tampoco reprochable, pues como la figura implica una sanción debe entenderse restringida. En cambio, la tercera línea legalista escogida por esta investigación sí ha sido criticada en la medida en que la Corte, ante la ausencia de normativa sobre la inexistencia de los negocios jurídicos, sorprende con que no es aplicable porque el fenómeno no está en el código, cuando no ha tenido ese reparo con otros institutos jurídicos que tampoco están en la ley. Y, en cuarto lugar, en la línea sobre la indemnización debida al arrendatario de local comercial cuando el dueño no da al inmueble el destino anunciado, también abdica de esta función creativa. "Donde el legislador no distingue no le es dado hacerlo al intérprete" es el argumento. Una salida en alto grado normativista para apartarse de la cual ya la Corte ha dado los primeros pasos en la sentencia de 14 de abril de 2008 (Corte Suprema de Justicia, Sala de Casación Civil, Expediente $N^{\circ} 00081$, 2008).

\section{LA TESIS EN LA POSMODERNIDAD: EL JUEZ CREA NORMAS GENERALES QUE PASAN A SER PARTE DE UNA MULTIPLICIDAD DE FUENTES DELDERECHO}

Si la Ilustración erigió como clásico el principio de completitud de la ley, la postmodernidad, de la mano de una pléyade de pensadores de las más diversas tendencias (en el trabajo se citan aquellos sin los cuales quizá no podría contarse la historia del Derecho actual), trajo consigo un regreso a la multiplicidad de fuentes legítimas del Derecho que implicó la aparición de un derecho pretoriano ultramoderno. A pesar de lo dispuesto en el artículo 17 del Código Civil colombiano, en la práctica, en Colombia los jueces producen reglas todo el tiempo, en tanto hoy la prohibición ha de entenderse morigerada por los principios constitucionales, bajo la luz de la sentencia C 461 (Corte Constitucional de Colombia, 2013), que declaró la exequibilidad del artículo citado.

La labor de dirimir los conflictos necesariamente va a tropezar con la falta de completitud de la ley. Y el camino a tomar es el emprendido por los magistrados de la Corte de Oro, que tuvieron la visión y la valentía de ensayar nuevas tendencias basadas en valores y principios. Así vieron la 
luz, en nuestro medio, institutos como el error común creador de derechos, el enriquecimiento injusto, el abuso del derecho, la presunción de culpa en las actividades peligrosas, la sociedad de hecho entre concubinarios, los contratos de adhesión y otros que implicaron una indiscutible creación judicial del Derecho, tarea para la cual nadie les discutió ni su competencia, ni su legitimidad política.

\section{LÍNEAS JURISPRUDENCIALES CREATIVAS DE LA CORTE SUPREMA DE JUSTICIA DE COLOMBIA, ATINENTES A CONFLICTOS CONTRACTUALES DE DERECHO PRIVADO}

La jurisprudencia ha creado reglas concretas para solucionar vacíos, incoherencias, antinomias, lagunas, ambigüedades, en fin, toda suerte de problemas que la ley ofrece. Y cumple la tarea, por lo general, sin reconocer que lo hace; o bajo eufemismos tales como "el espíritu de la ley...", "una interpretación sistemática...", "por extensión" o alguna otra expresión similar, en una admirable labor de creación del Derecho que en épocas recientes introdujo en el sistema reglas sobre disolución por mutuo disenso tácito, indexación, inmisión de obligados contractuales no celebrantes y otras en las que ha elaborado estatutos completos, a lo largo de toda su historia, como ocurre con la simulación, aunque también sin admitirlo.

La imagen legalista que se atribuye a la Sala Civil de la Corte Suprema de Justicia no resulta siempre ajustada a la realidad cuando se estudian las líneas jurisprudenciales atinentes a temas sustanciales. Varias líneas que en la investigación fueron clasificadas como textualistas, luego hubo necesidad de reclasificarlas como creativas. Así, valga como ejemplo, la línea acerca de la resolución de los contratos de compraventa por el no pago del precio. La tendencia inicial es la de alinear estas sentencias como textualistas, dado que la Corte misma resalta que "no puede sustituir al legislador"; pero el estudio pone al descubierto que, en realidad, la Corte creó una norma. Es más, ya identificada la regla, se aprecia como infortunada, porque no parece estar acompasada con el sistema jurídico colombiano, en la medida en que impone una sanción no prevista en la ley, la pérdida de la corrección monetaria para el incumplido. En la línea sobre dación en pago la Corte creó la norma según la cual la lesión enorme era aplicable a esta figura, para luego invertirla: no es aplicable la lesión enorme a la dación en pago. Ambas reglas son de creación jurisprudencial. Sin embargo, la Corte recalca su posición normativista, "Sería abrogar el derecho positivo vigente $\mathrm{y}$, al 
tiempo, sustituir al legislador en una función que sólo a él compete", dice.

A juicio de este trabajo, es posible identificar cuatro niveles de creación judicial del Derecho. En el más elemental, el juez crea la norma del caso por subsunción; la labor creativa es mínima; es el único nivel de creatividad reconocido por el modelo positivista normativista, que no le concede legitimidad sino para transformar la norma abstracta en norma concreta.

En el segundo nivel, el juez crea la norma del caso apoyado en las ya existentes, mediante herramientas como la analogía, o valido de argumentos lógicos como, a fortiori, ad maiore ad minus, ad absurdum, etc. Cuando lo hace, la Corte no ve su labor como creadora, sino como subsunción por extensión de la norma estatuida, aunque se reconoce legitimada para investigar el derecho. Es el nivel que ha tenido el derecho civil colombiano, en general, desde la Ley 153 de 1887, con importantes excepciones que alcanzan los dos niveles restantes.

En el tercer nivel, el juez crea la norma bien porque llena de contenido una norma ambigua (como lo hace con el inciso primero del artículo 1746 del Código Civil, en las restituciones consecuenciales de la nulidad), bien porque completa la norma insuficiente (como en la disolución por mutuo disenso tácito), bien porque interpreta los silencios de la ley. De las tres hipótesis, la última es muy problemática, pues al dejar de reconocer una prestación, porque la ley no la menciona, el juzgador, eventualmente contra el sistema jurídico, crea la norma según la cual el pretendido titular carece del derecho. Supone este juez que el legislador dejó el vacío a propósito, porque el tema era irrelevante, o porque debía excluirse, cuando el hecho pudo ocurrir, simplemente, por ignorancia, como pasa con los adelantos científicos y otros aspectos de nuestro tiempo que el legislador del siglo XIX no podía conocer. La sentencia, que dice negarse a crear una norma, crea la norma contraria a la que se le ruega. Tal cosa pasó en las de resolución del contrato de compraventa por el no pago del precio y en las de lesión enorme, corregida ya en punto de las prestaciones mutuas en la lesión enorme, pero que subsiste en el otro evento.

Y en el cuarto nivel la Corte crea la norma prácticamente de la nada, como en la simulación, o en la corrección monetaria, temas en los que ha construido verdaderos estatutos. Rara vez admite que lo hace; sin embargo, en las sentencias de 16 de mayo de 1968 (Gaceta Judicial, tomo 
CXXIV) y 30 de mayo de 1970 (Gaceta Judicial, tomo CXXXIV), se tomó la libertad de reseñar los enunciados prescriptivos que hasta esos momentos había hecho.

Las tendencias textualistas extremas no admiten ni siquiera el primer nivel, "sospechan incluso del precedente como fuente del Derecho, porque está infectado de creatividad" dice Posner (2011). Pero, como las leyes se hallan, por fuerza, impregnadas del halo constitucional, por irradiación, según afortunada expresión acuñada por el Tribunal Constitucional alemán ${ }^{3}$, el sistema seguramente avanzará hacia nuevas perspectivas acerca de esta tarea de las Cortes y, ojalá, hacia la explicitud de la misma. Pero ha quedado demostrado que no es plausible solución que el juez pase a ignorar un tema, so pretexto de no invadir la órbita de competencia del legislador, pues tal pasividad puede conducir a una norma implícita errada, como en la de resolución del contrato de compraventa, en lo atinente a la indexación de la parte pagada del precio, en que la Corte, por no crear una norma, crea otra, nada menos que de carácter sancionatorio, con lo cual ocurre una más grave holladura al orden jurídico, pues viola el principio de legalidad de las sanciones y, de paso, otros principios constitucionales.

\section{EL PRINCIPIO DE COMPLETITUD DE LA LEY FUE UN TRASPLANTE CULTURAL MÁS QUE NORMATIVO}

Con el artículo 17 del Código Civil colombiano ${ }^{4}$, traducción del 5 del $C o d e^{5}$, no cabría duda de la consagración en nuestro ámbito del principio de la completitud. Pero las normas decimonónicas nuestras, de finales del siglo, apuntaban en sentido contrario. Así, el artículo 32 del Código Civil contempló la posibilidad de que "no pudieren aplicarse las reglas de interpretación anteriores"; y brindó como solución atenerse al "modo que más conforme parezca al espíritu general de la legislación y a la equidad natural"; el artículo 5 de la Ley 153 de 1887 autorizó echar mano de la "equidad natural y la doctrina constitucional" para interpretar la ley cuando fuere oscura o incongruente; el artículo 7 de la misma ley prescribió, en forma un tanto evocativa del derecho norteamericano, que las normas constitucionales contentivas de los "derechos civiles y garantías sociales tiene(n) también fuerza legal"; y

3 BVerfGE 7, 198, 205, caso Lüth, enero 15 de 1958.

4 "Las sentencias judiciales no tienen fuerza obligatoria sino respecto de las causas en las que fueron pronunciadas. Es, por tanto, prohibido a los jueces proveer en los negocios de su competencia por vía de disposición general o reglamentaria", reza la norma.

5 "Il est défendu aux juges de prononcer par voie de disposition générale et réglementaire sur les causes qui leur sont soumises 》. 
el artículo 8 prescribió que "cuando no haya ley exactamente aplicable al caso controvertido, se aplicarán las leyes que regulen casos o materias semejantes, y en su defecto, la doctrina constitucional y las reglas generales de derecho". Con tales admoniciones no puede quedar más claro el planteamiento de la falta de completitud del código (Valencia \& Ortiz, 2008). En el contexto de la Ley 153 de 1887 parece lo obvio, dado que, a poco de expedido el Código Civil, ya fue necesario hacerle profundas reformas.

Pero, a pesar de las normas citadas, el principio de completitud se entronizó en nuestra cultura jurídica por virtud del uso de los tratadistas, de los jueces y de los dirigentes que lo pregonaron. Pero fue más un trasplante de un legado jurídico cultural que una consagración legislativa del principio, si se observan las normas acabadas de citar.

\subsection{Legitimidad de la función creativa de la Corte}

Dado que las relaciones entre los miembros del género humano están signadas por la complejidad y la diversidad, jamás será posible una norma que todo lo prevea, por sabio y dedicado que sea el legislador; siempre habrá vacíos y toda suerte de vicisitudes que obligan a la búsqueda de soluciones diferentes a las estatuidas y la Corte no puede eludir esa tarea creativa, por mucho que lo intente. Si no la hiciere, el Derecho no tendría vida, se anquilosaría y, ante la progresiva ineficacia material de las leyes, afectadas por la obsolescencia, imperaría la ley del más fuerte, o la anomia destruiría a las sociedades y a la humanidad misma. Por consiguiente, si la labor creativa de la Corte además de inevitable, resulta también indispensable, es necesario escudriñar los principios y reglas en los cuales se afinca la tarea.

Tomar el inciso primero del artículo 230 de la Constitución Política como una camisa de fuerza que impide reconocer como Derecho un enunciado que se halle por fuera de las normas estatuidas, es suponer que en ese inciso se halla toda la normativa constitucional, lo cual es absurdo, pues el mismo artículo, en el inciso segundo, abre un panorama indicador de que el sistema se halla lejos de ser pleno. Nótese que los cuatro criterios auxiliares que enuncia no lo son de la interpretación de la ley, sino de la "actividad judicial", con lo cual el propio constituyente reconoce la falta de completitud del conjunto de normas escrito.

Ahora, el juez actúa en nombre del Estado, luego no puede ignorar sus fines al tomar decisiones (artículo 2). Y mucho menos los valores y 
principios construidos por nuestra cultura, plasmados en normas superiores de carácter político producto de un largo proceso dialógico, denominado así por Habermas (2000), que trasciende los siglos, pero que es susceptible de identificar por el aparato judicial, ya que este, según Luhmann (2005), hace parte de un entramado social sometido a un proceso de aprendizaje propio de una esfera cultural que le sirve de contexto (Bordeau \& Teubner, 2000) Al igual que todo juez, la Corte Suprema de Justicia representa al sistema jurídico, no solo al inciso primero del artículo 230; y ha de acometer su labor de juzgamiento sin olvidarse de los valores que nuestra comunidad ha construido y respeta, tales como "la vida, la convivencia, el trabajo, la justicia, la igualdad, el conocimiento, la libertad y la paz" (preámbulo), "la dignidad humana", "la solidaridad" (artículo 1), "la prosperidad general, la garantía de los derechos, la convivencia pacífica y la vigencia de un orden justo" (artículo 2), los cuales sirven de norte en la búsqueda de solución a cualquier litigio. Y como al juez se ha confiado la salvaguarda de los derechos de las personas y de los principios constitucionales, no cabe duda de que su tarea creativa le es determinada por el sistema y, por tanto, es un poder-deber legítimo.

Además, la Corte no puede dejar de lado que la finalidad del proceso judicial es la de solucionar de la mejor manera posible los conflictos entre las personas. Y, sin apartarse del debido proceso, tal finalidad ha de ser propiciada mediante mecanismos que hagan valer el derecho sustancial sobre el procesal, como lo postula la Constitución Política (1991) en su artículo 228; de modo que puedan ser materializados los más caros valores de nuestro sistema. La necesaria ponderación de fines, principios y valores, comporta una gran transformación de la función judicial, pues el fallador tiene ahora, no sólo la potestad sino la carga de auscultarlos y encontrar que tengan operatividad en cada caso.

Incluso si los intereses en contienda son puramente patrimoniales, el sistema político impele al juez a considerar y llenar de contenido principios como los fines del Estado del artículo segundo atrás citados, la protección de los derechos fundamentales (artículo 85), la presunción de buena fe (83), la función social y ecológica de la propiedad (58) y otros de igual trascendencia. La ponderación de los principios y de los valores constitucionales encaminará al juez, sin duda, a acoger soluciones que consulten mejor la pretensión de corrección del Derecho (Alexy \& Bulygin, 2001). Por tanto, cuando el juzgador se muestra atado por el artículo 17, sea que lo cite o no, probablemente ocurre que su percepción le indica que debería crear la regla, pero no se atreve; y la 
decisión inicua sobrevendría por supuesta culpa atribuible al legislador. A juicio de este trabajo, el reproche más bien lo merece el juez, en tanto el orden jurídico actual sí le brinda las herramientas para entender otro alcance de sus deberes constitucionales y legales. De allí que señalara la Corte Constitucional en la sentencia C-836 de 2001: "más fácil se concibe un sistema jurídico sin legislador que sin jueces".

Si el juez tiene el deber de hallar la salida correcta al conflicto, no tendrá opción diferente a la de crear el Derecho en los casos de insuficiencia o de silencio. En consecuencia, la creación del Derecho es una función del juez y, por tanto, hace parte de sus deberes (Posner, 2011). Pero a la tarea, el ordenamiento jurídico ha puesto cotas que el juez no puede sobrepasar. No se trata de una potestad ilimitada ni discrecional. En el área relacionada con juicios contractuales de derecho privado, este trabajo ha detectado limitantes de la tarea en temas como sanciones (el juez no puede crearlas), causales de nulidad (también ha de limitarse a las que consagra la ley), caducidades o términos de prescripción (son sanciones y el juez no puede dar a estas un alcance diferente, en cargas, para la una, o conteo de términos, para la otra), formalidades (de acuerdo con el artículo 84 de la Constitución Política, no podría un juez imponerlas, sin texto legal), la definición de las reglas que disciplinan el perfeccionamiento de un negocio es asunto que no define el juez, sino la ley o las partes y, también, la configuración de contratos impuestos por vía judicial es cuestión de reserva legal.

Entonces, la norma que el juez elabore ha de armonizar con el sistema y el juez tiene la carga de convencer que así es, primero a los usuarios de la justicia en el caso; luego, a los demás jueces y a los juristas y, por último, a la comunidad en general (Perelman, 1979). Ahora, no cabe duda de que el riesgo de error es alto, pero no queda otro camino que confiar en la razonabilidad del juez, principalmente de la Corte Suprema de Justicia.

\section{CONCLUSIONES}

En lo que sigue se mostrará una síntesis de las conclusiones de la investigación.

Se logró demostrar que la Sala Civil de la Corte Suprema de Justicia de Colombia ha creado normas que hoy integran nuestro sistema jurídico, con alcance general.La Corte suele negar en sus sentencias que crea normas pues supone que carece de legitimidad para esa tarea. "No puede la Corte sustituir al legislador", expresa. 
Aunque se esfuerce por no hacerlo, la Corte crea normas; a veces, exactamente la norma contraria a aquella de la que dice huir. La regla prohibitiva no pudo impedir que los jueces creasen normas.

Hay eventos en los cuales la Corte no crea derecho, ni debe hacerlo, porque el sistema jurídico le impone atenerse al estatuido, bajo razones garantistas. La creación judicial de normas no contraría principios constitucionales; al contrario, es indispensable para evitar el hollamiento de derechos constitucionales.

Las reglas pretoriales han de estar acordes con el sistema jurídico en general. De las normas y principios constitucionales que legitiman la función e imponen a las Cortes el poder-deber de crear una disposición, se deducen también los linderos de la tarea.

La función creadora implica una carga de razonabilidad para el juez, pues ha de explicar con suficiencia el porqué de su proceder. No parece posible hallar mejor instrumento para la interdicción de la arbitrariedad.

\section{REFERENCIAS BIBLIOGRÁFICAS}

ALEXY, Robert y BULYGIN, Eugenio. (2001). La pretensión de corrección del derecho. La polémica sobre la relación entre derecho y moral. Traducción de Paula Gaido. Bogotá, Universidad Externado de Colombia

BOURDIEU, Pierre y TEUBNER, Gunther. (1985). La fuerza del Derecho. Bogotá, Siglo del Hombre - Universidad de los Andes, 2000, p. 113; SMEND, Rudolf. Constitución y derecho constitucional. Traducción de José María Beneyto Pérez. Madrid: Centro de Estudios Constitucionales

Corte Constitucional de Colombia, Sentencia C-836 de agosto 9 de 2001, M.P. Rodrigo Escobar Gil.

GENY, François. (1925). Método de interpretación y fuentes en derecho privado. Segunda edición. Madrid, Reus.

HABERMAS, JURGEN. (2000). Facticidad y validez. Sobre el derecho y el estado democrático de Derecho en términos de teoría del discurso. Madrid, Trotta 
JEAN-DENIS BREDIN, (2004). Présentation. En: FRANCIA. Code Civil des Français Bicentenaire 1804. Paris, Dalloz.

LAPORTA, Francisco J. (2007). El imperio de la ley. Una visión actual. Madrid, Trotta

LUHMANN, Niklas. (2005). El derecho de la sociedad. Barcelona, Herder

PERELMAN, Chaïm. (1979). La lógica jurídica y la nueva retórica. Traducción de Luis Díez-Picazo. Madrid, Civitas

POSNER, Richard. (2011). Cómo deciden los jueces. Traducción de Victoria Roca Pérez. Madrid, Marcial Pons

RECASÉNS SICHES. Luis. (1980). Nueva filosofía de la interpretación del derecho. México, Editorial Porrúa

SIMON, Dieter. (1985). La independencia del juez. Barcelona, Ariel

VALENCIA ZEA, Arturo y ORTIZ MONSALVE, Álvaro. (2008) Derecho civil. Parte general y personas. Tomo I, undécima edición. Bogotá, Temis, 2008

ZIMMERMANN, Reinhard. (2010). Derecho romano, derecho contemporáneo, derecho europeo: la tradición del derecho civil en la actualidad. Traducción de Javier M. Rodríguez Olmos. Bogotá, Universidad Externado de Colombia 